\title{
Specific detection and differentiation of Ochrobactrum anthropi, Ochrobactrum intermedium and Brucella spp. by a multi-primer PCR that targets the recA gene
}

\author{
Holger Christian Scholz, ${ }^{1}$ Martin Pfeffer, ${ }^{1}$ Angela Witte, ${ }^{2}$ \\ Heinrich Neubauer, ${ }^{3}$ Sascha Al Dahouk, ${ }^{4}$ Ulrich Wernery ${ }^{5}$ \\ and Herbert Tomaso ${ }^{1}$
}

Correspondence
Holger Christian Scholz
Holger1Scholz@bundeswehr.org

Received 11 July 2007

Accepted 17 September 2007

\author{
${ }^{1}$ Bundeswehr Institute of Microbiology, Neuherbergstrasse 11, D-80937 Munich, Germany \\ ${ }^{2}$ Institute of Microbiology and Genetics, University of Vienna, Dr Bohr-Gasse 9, A-1030 Vienna, \\ Austria \\ ${ }^{3}$ Friedrich Loeffler Institute, Institute of Bacterial Infections and Zoonoses, Federal Research \\ Institute for Animal Health, Naumburger Strasse 96a, D-07743 Jena, Germany \\ ${ }^{4}$ RWTH University of Aachen, Department of Internal Medicine III, Pauwelsstraße 30, \\ D-52074 Aachen, Germany \\ ${ }^{5}$ Central Veterinary Research Laboratory, PO Box 597, Dubai, United Arab Emirates
}

\begin{abstract}
Ochrobactrum anthropi, Ochrobactrum intermedium and Brucella spp. are phenotypically and genetically closely related pathogens that may cause disease with similar clinical presentation. Consequently, difficulties in their identification and differentiation have been reported. In this study, a sensitive recA gene-based multi-primer single-target PCR (MP-ST-PCR) was developed that allowed the specific detection and differentiation of these clinically relevant pathogens. The specificity of the assay was evaluated using a representative panel of 50 O. anthropi and 16 O. intermedium strains and the type strains of all Brucella spp. Detection limits for purified DNA from O. anthropi, O. intermedium and Brucella melitensis were 100, 10 and $100 \mathrm{fg}$, respectively. Brucella DNA was also successfully detected in various clinical specimens from a human patient with culture-proven brucellosis and from a Brucella-infected sheep and its aborted fetuses. The sensitivity of the MP-ST-PCR was comparable to that of an evaluated in-house Brucella real-time PCR assay. The developed assay closes a diagnostic gap and provides a simple but robust tool for the sensitive detection and correct identification of O. anthropi, O. intermedium and Brucella spp.
\end{abstract}

\section{INTRODUCTION}

Ochrobactrum and Brucella are genetically closely related genera of the family Brucellaceae within the class Alphaproteobacteria (Velasco et al., 1998), with Ochrobactrum intermedium, the closest relative to Brucella, sharing $98.8 \%$ rRNA gene similarity with Brucella spp.

Whereas brucellae are well recognized as important pathogens that cause brucellosis in man and many animal species, Ochrobactrum anthropi and O. intermedium have only recently emerged as human pathogens (Alnor et al., 1994; Möller et al., 1999; Mahmood et al., 2000;

Abbreviations: $C_{t}$, cycle threshold; MP-ST-PCR, multi-primer singletarget PCR.
Apisarnthanarak et al., 2005; Vaidya et al., 2006; Kämpfer et al., 2007). In the past, O. anthropi and O. intermedium have been regarded as opportunistic human pathogens of low virulence, infecting only immunocompromised patients with underlying diseases. Recent reports on Ochrobactrum infections, however, have demonstrated the occurrence of severe $O$. anthropi infections in immunocompetent hosts without underlying diseases with a clinical presentation similar to brucellosis (Kettaneh et al., 2003; Romero Gomez et al., 2004; Perez-Blanco et al., 2005; Ozdemir et al., 2006). A report on a pelvic abscess in an immunocompetent host and a comprehensive review of the literature on $O$. anthropi infections in patients with normal immune status was recently published by Vaidya et al. (2006). 
Because of the clinical relevance of Brucella infections and the potential use of Brucella as a biological agent (Pappas et al., 2006), a battery of PCR assays for the specific detection of Brucella spp. has been developed in recent years (Al Dahouk et al., 2004, 2007; Garcia-Yoldi et al., 2006). However, in many clinical laboratories, the initial diagnosis is made by conventional identification methods, mainly culture and biochemical analysis using commercially available test systems. These test systems often do not allow correct identification of the agent, and consequently misidentifications of Brucella spp. as O. anthropi (Elsaghir \& James, 2003) or O. intermedium (Hubalek et al., 2007) have been reported. Furthermore, as O. anthropi is the only species of Ochrobactrum in the database of commercially available test systems such as API 20NE, differentiation of $O$. anthropi and O. intermedium is impossible (Teyssier et al., 2005; Kämpfer et al. 2007). Likewise, O. intermedium was recently misidentified as $O$. anthropi in a severely diseased patient with a pelvic abscess using the API 20NE test and partial 16S rRNA gene sequencing (Vaidya et al., 2006; Kämpfer et al. 2007). In this case, partial 16 S rRNA gene sequencing was misleading because of the high sequence identity of $>98 \%$ between $O$. anthropi and $O$. intermedium.

Reports on the misidentification of $O$. anthropi, $O$. intermedium and Brucella spp. emphasize the urgent need for a diagnostic tool that allows the correct identification and differentiation of these pathogens. Accordingly, we have developed a sensitive multi-primer single-target PCR (MP-ST-PCR) based on sequence variations in the recA gene that allows the accurate identification and differentiation of O. anthropi, O. intermedium and Brucella spp. in a single reaction.

\section{METHODS}

Bacterial strains. A total of 71 Ochrobactrum strains (50 O. anthropi, $16 O$. intermedium and one each of Ochrobactrum tritici, Ochrobactrum oryzae, Ochrobactrum grignonense, Ochrobactrum gallinifaecis and Ochrobactrum lupini) and the type strains of the eight Brucella species (Brucella melitensis, Brucella abortus, Brucella suis, Brucella ovis, Brucella canis, Brucella neotomae, Brucella ceti and Brucella pinnipedialis) were examined (Table 1). An additional 23 strains of closely related or clinically relevant bacteria were used as a negative-control panel.

Strains were obtained from the American Type Culture Collection (ATCC), the Laboratorium voor Microbiologie (BCCM/LMG), the Culture Collection University of Goeteborg (CCUG), the National Collection of Type Cultures (NCTC), the German Collection of Micro-organisms and Cell Cultures (DSMZ) and the Czech Collection of Micro-organisms (CCM). Strains TA13, E276, RR, TD30 and TM73 were kindly provided by A. Sessitsch (ARC Seibersdorf Research GmbH, Seibersdorf, Austria). Strains ALM4, OaC13a, CLM6, CLM7, OpsIndien, OiC8-5, OiC8-6 and OgA9a were kindly provided by M. Lebuhn (GSF-Forschungszentrum für Umwelt und Gesundheit, Munich, Germany). Strain LUP $21^{\mathrm{T}}$ was provided by M. E. Trujillo (Departamento de Microbiologia, Salamanca, Spain). Strain RMA 16994 was kindly provided by E. J. Goldstein and S. A. Vaidya (Medical Scientist Training Program, University of California,
Los Angeles, USA). The type strains of O. anthropi (LMG $3331^{\mathrm{T}}$, CCUG $24695^{\mathrm{T}}$ ) and O. intermedium (LMG $3301^{\mathrm{T}}$, CCUG $24694^{\mathrm{T}}$ ) were each obtained from two different strain collections, CCUG and LMG, respectively.

DNA preparation from pure cultures. One distinct colony of each strain was transferred from an agar plate to $200 \mu$ lysis buffer $[5 \times$ buffer D (PCR Optimization kit; Invitrogen) diluted 1:5 in doubledistilled $\mathrm{H}_{2} \mathrm{O}, 0.5 \%$ Tween 20 (ICI American), $12 \mathrm{U}$ proteinase $\mathrm{K}$ (Roche Diagnostics)]. After incubation at $56{ }^{\circ} \mathrm{C}$ for $1 \mathrm{~h}$ followed by inactivation for $10 \mathrm{~min}$ at $95{ }^{\circ} \mathrm{C}, 2 \mu \mathrm{l}$ of the cleared lysate was used as template in the PCR assays.

For determination of the PCR detection limits, the type strains $B$. melitensis $16 \mathrm{M}^{\mathrm{T}}$, O. anthropi LMG $3331^{\mathrm{T}}$ and O. intermedium LMG $3301^{\mathrm{T}}$ were grown at $37{ }^{\circ} \mathrm{C}$ in liquid medium to $\mathrm{OD}_{600} 0.7$ (midexponential growth phase). Genomic DNA was prepared with a DNeasy Blood \& Tissue kit (Qiagen) according to the manufacturer's instructions. PCR was carried out as described below.

DNA preparation from clinical samples. Total DNA was prepared from various formalin-inactivated $(10 \%, \mathrm{v} / \mathrm{v})$ clinical samples and body fluids of an aborting sheep with brucellosis and its two fetuses. Specimens examined were: placental fluid, serum, urine, stomach content, placenta, lung, liver, spleen, uterus, udder and kidney (see Fig. 2(a), left panel).

Additionally, DNA was prepared from liver biopsy material of a human patient with culture-proven brucellosis. After removing the formalin by washing twice in $10 \mathrm{ml}$ deionized water and further incubation in sterile saline overnight at $4{ }^{\circ} \mathrm{C}, 50 \mathrm{mg}$ of each sample was homogenized in $500 \mu \mathrm{l}$ PBS (pH 7.5) using a Biol01 Fast Prep System (Qbiogene). Total DNA was prepared from $100 \mu$ homogenized tissue using a DNeasy Tissue kit (Qiagen). The DNA was eluted twice with $60 \mu$ d double-distilled $\mathrm{H}_{2} \mathrm{O}$, of which $5 \mu$ l was used in PCRs.

Primer design and MP-ST-PCR. Primers were designed on the basis of a multi-sequence alignment of known recA gene sequences from Ochrobactrum spp. and Brucella spp. (Scholz et al., 2006; H. C. Scholz, unpublished data). The GenBank accession numbers of the various recA genes are given in Table 1. Details of the primers and amplification sizes of the partial recA gene sequences from $O$. anthropi, O. intermedium and Brucella spp. are given in Table 2.

PCR conditions were optimized for each primer pair using purified template DNA from O. anthropi LMG $3331^{\mathrm{T}}$, O. intermedium LMG $3301^{\mathrm{T}}$ and B. melitensis $16 \mathrm{M}^{\mathrm{T}}$ prior to use in MP-ST-PCR. Optimized MP-ST-PCR was performed in $50 \mu \mathrm{l}$ Ready-to-go MasterMix (Eppendorf) using $15 \mathrm{pmol}$ each primer. Amplification was carried out in a Perkin-Elmer GeneAmp 2400 thermal cycler with 30 cycles of $30 \mathrm{~s}$ denaturation at $94{ }^{\circ} \mathrm{C}, 40 \mathrm{~s}$ annealing at $62{ }^{\circ} \mathrm{C}$ and $1 \mathrm{~min}$ elongation at $72{ }^{\circ} \mathrm{C}$, with a final elongation step of $7 \mathrm{~min}$ at $72{ }^{\circ} \mathrm{C}$. The expected sizes of the amplification products were 544, 402 and $167 \mathrm{bp}$ for $O$. anthropi, O. intermedium and Brucella spp., respectively. PCR products were separated by $1.5 \%(\mathrm{w} / \mathrm{v})$ agarose gel electrophoresis in $1 \times$ Tris/borate/EDTA running buffer at a constant voltage of $120 \mathrm{~V}$ for $1 \mathrm{~h}$. Fragments were visualized with UV light after staining in ethidium bromide.

Detection limit of the MP-ST-PCR. Purified DNA preparations of O. anthropi LMG $3331^{\mathrm{T}}$, O. intermedium LMG $3301^{\mathrm{T}}$ and B. melitensis $16 \mathrm{M}^{\mathrm{T}}$ were quantified in triplicate using an ND-1000 UV/Vis spectrophotometer (NanoDrop Technologies). The detection limits were determined three times by analysing a dilution series of the prepared DNA in PCR-grade water ranging from $1 \mathrm{ng}$ to $1 \mathrm{fg}$. In the first step, the detection limit for each primer pair was determined separately using $1 \mu \mathrm{l}$ of the corresponding template DNA of each 
Table 1. List of strains analysed in this study

NA, Not available.

\begin{tabular}{|c|c|c|c|c|c|c|}
\hline \multirow[t]{2}{*}{ Strain } & \multirow[t]{2}{*}{ Source } & \multirow[t]{2}{*}{ Species } & \multirow{2}{*}{$\begin{array}{c}\text { recA GenBank } \\
\text { accession number }\end{array}$} & \multicolumn{3}{|c|}{ MP-ST-PCR result } \\
\hline & & & & Brucella spp. & O. anthropi & O. intermedium \\
\hline \multicolumn{7}{|l|}{ Brucella } \\
\hline NCTC $10093^{\mathrm{T}}$ & Cattle & B. abortus & AM113730 & + & - & - \\
\hline ATCC $23365^{\mathrm{T}}$ & Dog & B. canis & AM113731 & + & - & - \\
\hline ATCC $23456^{\mathrm{T}}$ & Goat & B. melitensis & AM087912 & + & - & - \\
\hline ATCC $23459^{\mathrm{T}}$ & Rat & B. neotomae & AM113732 & + & - & - \\
\hline ATCC $25840^{\mathrm{T}}$ & Sheep & B. ovis & AM113733 & + & - & - \\
\hline NCTC $10316^{\mathrm{T}}$ & Wild boar & B. suis & AM113734 & + & - & - \\
\hline NCTC $12890^{\mathrm{T}}$ & Sea lion & B. pinnipedialis & AM113735 & + & - & - \\
\hline NCTC $12891^{\mathrm{T}}$ & Whale & B. ceti & AM113736 & + & - & - \\
\hline \multicolumn{7}{|l|}{ Ochrobactrum } \\
\hline LMG 33 & Hospital environment & O. anthropi & AM422738 & - & + & - \\
\hline LMG 35 & Dextran & O. anthropi & AM422745 & - & + & - \\
\hline LMG 371 & NA & O. anthropi & AM422746 & - & + & - \\
\hline LMG 394 & Human cerebrospinal fluid & O. anthropi & AM422747 & - & + & - \\
\hline LMG 395 & Human incision & O. anthropi & AM422748 & - & + & - \\
\hline LMG 2134 & Unused contact lens & O. anthropi & AM422880 & - & + & - \\
\hline LMG 2136 & Industrial dust & O. anthropi & AM422736 & - & + & - \\
\hline LMG 3298 & Environment & O. anthropi & AM422737 & - & + & - \\
\hline LMG 3305 & Hospital environment & O. anthropi & AM422739 & - & + & - \\
\hline LMG 3307 & Paint & O. anthropi & AM422740 & - & + & - \\
\hline LMG 3309 & Human tracheal secretion & O. anthropi & AM422741 & - & + & - \\
\hline LMG 3312 & Wheat rhizoplane & O. anthropi & AM422742 & - & + & - \\
\hline LMG 3313 & Soil & O. anthropi & AM422743 & - & + & - \\
\hline LMG 3329 & Human faeces & O. anthropi & AM422744 & - & + & - \\
\hline LMG $3331^{\mathrm{T}}$ & Sewage plant in Bora & O. anthropi & AM087899 & - & + & - \\
\hline LMG 3333 & Blood culture & O. anthropi & AM087908 & - & + & - \\
\hline LMG 5140 & Estuary sediment & O. anthropi & AM158983 & - & + & - \\
\hline LMG 5438 & Human vagina & O. anthropi & AM422749 & - & + & - \\
\hline LMG 5440 & Human peritoneal fluid & O. anthropi & AM422750 & - & + & - \\
\hline LMG 5441 & Human blood & O. anthropi & AM422751 & - & + & - \\
\hline LMG 5442 & Human blood & O. anthropi & AM422752 & - & + & - \\
\hline LMG 5444 & Human & O. anthropi & AM422753 & - & + & - \\
\hline LMG 7991 & Human eye & O. anthropi & AM087909 & - & + & - \\
\hline LMG 18952 & Human blood & O. anthropi & AM422734 & - & + & - \\
\hline LMG 18953 & Arsenite cattle-dip tray & O. anthropi & AM422735 & - & + & - \\
\hline CCUG 772 & Human blood & O. anthropi & AM422728 & - & + & - \\
\hline CCUG 1047 & Human abscess & O. anthropi & AM422707 & - & + & - \\
\hline CCUG 1076 & Hospital environment & O. anthropi & AM422708 & - & + & - \\
\hline CCUG 1838 & NA & O. anthropi & AM422714 & - & + & - \\
\hline CCUG 7349 & NA & O. anthropi & AM422727 & - & + & - \\
\hline CCUG 12303 & NA & O. anthropi & AM422709 & - & + & - \\
\hline CCUG 12860 & Human blood & O. anthropi & AM422710 & - & + & - \\
\hline CCUG 13083 & Human peritoneal fluid & O. anthropi & AM422711 & - & + & - \\
\hline CCUG 16508 & $\mathrm{NA}$ & O. anthropi & AM422712 & - & + & - \\
\hline CCUG 17894 & Contaminant & O. anthropi & AM422713 & - & + & - \\
\hline CCUG 18525 & Unused contact lens & O. anthropi & AM422715 & - & + & - \\
\hline CCUG 18681 & Industrial dust & O. anthropi & AM422716 & - & + & - \\
\hline CCUG 20020 & Human blood & O. anthropi & AM422717 & - & + & - \\
\hline CCUG 20050 & Human blood & O. anthropi & AM422718 & - & + & - \\
\hline CCUG $24695^{\mathrm{T}}$ & Human & O. anthropi & AM422719 & - & + & - \\
\hline CCUG 25934A & Human cerebrospinal fluid & O. anthropi & AM422720 & - & + & - \\
\hline CCUG 28303 & Human blood & O. anthropi & AM422721 & - & + & - \\
\hline CCUG 30656B & Human eye & O. anthropi & AM422722 & - & + & - \\
\hline
\end{tabular}


Table 1. cont.

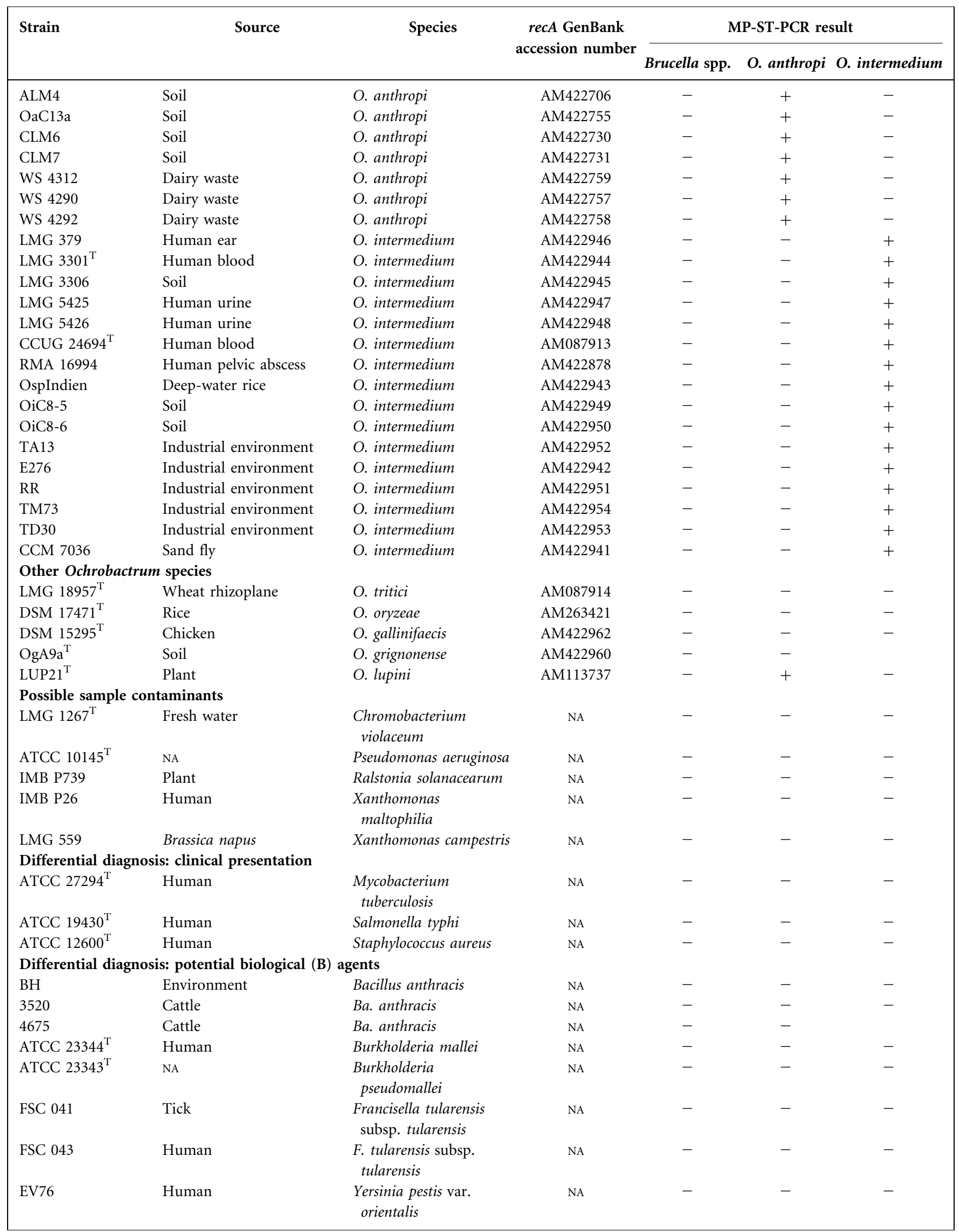


Table 1. cont.

\begin{tabular}{|c|c|c|c|c|c|c|}
\hline \multirow[t]{2}{*}{ Strain } & \multirow[t]{2}{*}{ Source } & \multirow[t]{2}{*}{ Species } & \multirow{2}{*}{$\begin{array}{c}\text { recA GenBank } \\
\text { accession number }\end{array}$} & \multicolumn{3}{|c|}{ MP-ST-PCR result } \\
\hline & & & & Brucella spp. & O. anthropi & O. intermedium \\
\hline Exu 21 & Human & Y. pestis var. orientalis & NA & - & - & - \\
\hline PKH4 & Human & Y. pestis var. medievalis & NA & - & - & - \\
\hline
\end{tabular}

dilution. In the MP-ST-PCR, the six primers were mixed in equal amounts and template DNA from O. anthropi LMG $3331^{\mathrm{T}}, O$. intermedium $\mathrm{LMG} 3301^{\mathrm{T}}$ or $B$. melitensis $16 \mathrm{M}^{\mathrm{T}}$ was added. Amplification products were analysed by electrophoresis through a $1.5 \%$ agarose gel, followed by ethidium bromide staining and visualization with UV light.

Brucella-specific real-time PCR. An in-house LightCycler realtime PCR was used for the detection of Brucella DNA in clinical samples. This PCR was evaluated recently (Al Dahouk et al., 2007) and uses the specific primers B4/B5, originally developed by Baily et al. (1992), which targets the omp31 gene of Brucella spp., in combination with Brucella-specific hybridization probes. Briefly, a single-tube duplex LightCycler PCR was performed using a FastStart DNA Hybridization Probes kit (Roche Diagnostics). The $20 \mu \mathrm{l}$ reaction mixture contained $2.5 \mathrm{mM} \mathrm{MgCl}, 2 \mu 10 \times$ reaction mix, $0.5 \mu \mathrm{l}$ each primer $\left(20 \mathrm{pmol} \mu^{-1}\right), 0.5 \mu \mathrm{l}$ each hybridization probe $\left(8 \mathrm{pmol} \mu \mathrm{l}^{-1}\right)$ and $2 \mu \mathrm{l}$ template DNA. Cycling was started with a 10 min denaturation step at $95{ }^{\circ} \mathrm{C}$, followed by 45 cycles of $10 \mathrm{~s}$ denaturation at $95{ }^{\circ} \mathrm{C}, 10 \mathrm{~s}$ annealing at $55{ }^{\circ} \mathrm{C}$ and $12 \mathrm{~s}$ extension at $72{ }^{\circ} \mathrm{C}$. As an internal amplification control, we included a bacteriophage $\lambda$ PCR system as described previously (Tomaso et al., 2003). No-template controls containing $2 \mu \mathrm{l}$ molecular-grade water instead of DNA and positive controls containing Brucella DNA of the reference strains B. melitensis $16 \mathrm{M}^{\mathrm{T}}$ (biovar 1), B. abortus 1119-3 (biovar 1) and/or B. suis 1330 (biovar 1) were included in each run to detect any amplicon contamination or amplification failure. Temperature transition rates were set at $20{ }^{\circ} \mathrm{C} \mathrm{s}^{-1}$. Fluorescence values were measured during each cycle at 640 and $705 \mathrm{~nm}$. Melting curves were generated by continuous measurement of fluorescence while raising the temperature from 45 to $95{ }^{\circ} \mathrm{C}$ with a transition rate of $0.2{ }^{\circ} \mathrm{C} \mathrm{s}^{-1}$. Data analysis was performed using LightCycler software version 3.32. The second-derivative maximum algorithm was used to calculate the cycle threshold $\left(C_{\mathrm{t}}\right)$ value. Primer sequences and hybridization probes are listed in Table 2.

\section{RESULTS AND DISCUSSION}

Brucella and Ochrobactrum are phenotypically and genetically closely related micro-organisms that may cause diseases with similar clinical presentation (Elsaghir \& James, 2003; Vaidya et al., 2006). Although Brucella and Ochrobactrum can be differentiated phenotypically by means of their growth behaviour, motility, lysis by Brucella-specific bacteriophages and agglutination with Brucella-specific antisera, misidentification of these organisms using biochemical test systems such as API 20NE has been reported (e.g. Elsaghir \& James, 2003; Hubalek et al., 2007). Currently, no PCR assay is available for the discrimination of $O$. anthropi, O. intermedium and Brucella spp. Thus, the aim of this study was to establish and evaluate a discriminatory PCR assay for the sensitive and specific detection of each of these pathogens. For this purpose, the recA gene was selected as the target gene, as it is highly conserved between Ochrobactrum and Brucella but exhibits enough stable nucleotide substitutions to establish a discriminatory PCR assay between Ochrobactrum and Brucella and also between O. anthropi, O. intermedium and other non-pathogenic Ochrobactrum spp. (Scholz et al., 2006). In a recent study, the recA genes of 106 Ochrobactrum strains and the Brucella type strains were

Table 2. PCR primers used in this study

Abbreviations: FL, fluorescein; LC Red640, LightCycler Red640.

\begin{tabular}{|c|c|c|c|c|}
\hline Organism & Primer/probe & Sequence $\left(5^{\prime} \rightarrow 3^{\prime}\right)$ & Nucleotide position & Amplicon (bp) \\
\hline \multicolumn{5}{|l|}{ MP-ST-PCR } \\
\hline \multirow[t]{2}{*}{ O. anthropi } & Anth-f & GCAAGCTGGGTGTCGATCTGG & $347-367$ & 544 \\
\hline & Anth-r & TTCTCGACGACACCGGCCTTTA & $890-869$ & \\
\hline \multirow[t]{2}{*}{ O. intermedium } & Inter-f & CGGCGTTGGTGGCTTGCCTAA & $186-206$ & 402 \\
\hline & Inter-r & GGAACGAGAGATAGACGCGGTA & $588-567$ & \\
\hline \multirow[t]{2}{*}{ Brucella spp. } & Bruc-f & AACCACGCTTGCCTTGCACACC & $249-270$ & 167 \\
\hline & Bruc-r & TTTCAAGCGCCTGTTCACCCG & $395-415$ & \\
\hline \multicolumn{5}{|l|}{ Real-time PCR } \\
\hline \multirow[t]{2}{*}{ Primers } & B4 & TGGCTCGGTTGCCAATATCAA & & \\
\hline & B5 & CGCGCTTGCCTTTCAGGTCTG & & \\
\hline \multirow[t]{2}{*}{ Probes } & BruFL & AGGCAACGTCTGACTGCGTAAAGCC-FL & & \\
\hline & BruLC & LC Red640-ACTCCAGAGCGCCCGACTTGATCG & & \\
\hline
\end{tabular}


sequenced and analysed in detail (H. C. Scholz et al., unpublished data). In the present study, we used this information to construct O. anthropi-, O. intermediumand Brucella-specific primers to set up and evaluate a differentiating PCR for these pathogens.

To assess the specificity of the developed MP-ST-PCR, the type strains of each Brucella species and a collection of 50 $O$. anthropi and $16 \mathrm{O}$. intermedium strains from both clinical and environmental sources, including one isolate (RMA 16994) from a recently reported severe O. anthropi infection in an immunocompetent host (Vaidya et al., 2006), were used (Table 1). The negative panel comprised 23 strains of closely related organisms, including the type strains of a number of Ochrobactrum spp., and other diagnostically relevant bacteria.

In the first step, the primer pairs were tested in separate STPCR for optimization of the cycle conditions and determination of the detection limit for each PCR. As expected, specific fragments of 544, 402 and $167 \mathrm{bp}$ were amplified using template DNA from all tested $O$. anthropi, $O$. intermedium and Brucella strains, respectively, using the appropriate primer pairs (data not shown). Each primer pair was specific for its template and did not amplify recA gene sequences from other bacteria, with the exception of $O$. lupini, which yielded a $544 \mathrm{bp}$ fragment with the $O$. anthropi-specific primers (Table 1). However, O. lupini is a highly adapted plant bacterium infecting only the roots of Lupinus albus, and thus does not interfere with the diagnosis of brucellosis or Ochrobactrum infections. Strain RMA 16994, initially identified by Vaidya et al. (2006) as O. anthropi, was positive in the O. intermedium PCR but not in the O. anthropi-specific PCR (Table 1). This is in agreement with a recent detailed molecular analysis, which demonstrated that this strain is indeed a member of the species $O$. intermedium (Kämpfer et al., 2007).

The detection limits in single PCR were 10, 10 and $100 \mathrm{fg}$ for O. anthropi, O. intermedium and Brucella spp., corresponding to 2,2 and 20 genome equivalents, respectively. MP-ST-PCR analysis using a mixture of equal amounts of each primer also resulted in the amplification of the expected products. Additional bands as a result of interfering primers were not observed. The detection limit of $O$. anthropi in the MP-ST-PCR was reduced by a factor of $10(100 \mathrm{fg})$, whereas the other detection limits were unaffected. The detection limits for $O$. anthropi, $O$. intermedium and B. melitensis of the MP-ST-PCR are shown in Fig. 1. No amplification was detected with template DNA of the other bacteria investigated.

Specific amplification products were also generated when mixed-template DNA from Brucella spp. with either $O$. anthropi or O. intermedium was used (data not shown). The detection limit was not reduced using this mixedtemplate DNA. A mixture of Brucella spp. together with DNA from $O$. anthropi and $O$. intermedium resulted in strong primer interference, giving uninterpretable results. However, this was only a theoretical scenario; in practice, it is unlikely that two of these agents, and even less three, would be co-isolated from one patient. However, the multiplex PCR may help to identify laboratory-derived cross-contamination of these organisms.

Brucella DNA from clinical material was detected using an in-house real-time LightCycler PCR that has been evaluated recently (Al Dahouk et al. 2007) and compared with the novel MP-ST-PCR described here. Template DNA was prepared from various clinical specimens from a sheep and its fetuses with culture-proven brucellosis (Fig. 2). Realtime PCR was carried out with template DNA from 31 different clinical samples using 45 cycles of amplification (Fig. 2a). Template DNAs that were positive in this PCR (nos 2, 4, 6, 8, 9, 10,11, 17 and 23) were subjected to the MP-ST-PCR using 37 amplification cycles. In this PCR, samples with a $C_{\mathrm{t}}$ value of $<37$ reacted positively (Fig. $2 \mathrm{~b}$, nos 2, 8, 9, 10 and 11). A faint band was visible with template $6\left(C_{\mathrm{t}}\right.$ value of 37$)$ in the MP-ST-PCR (Fig. 2b). (a)

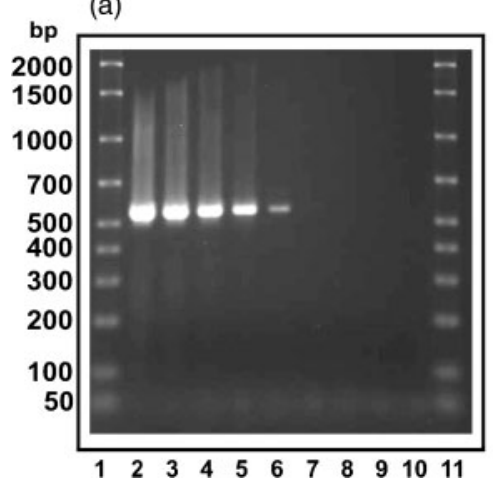

(b)

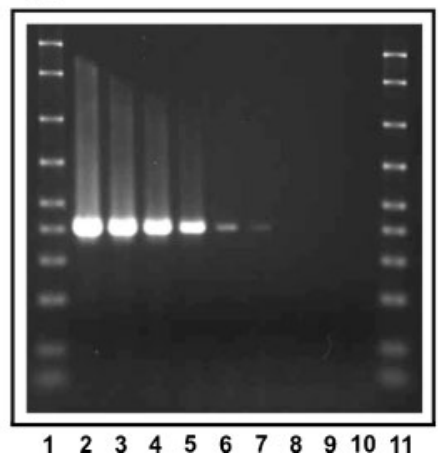

(c)

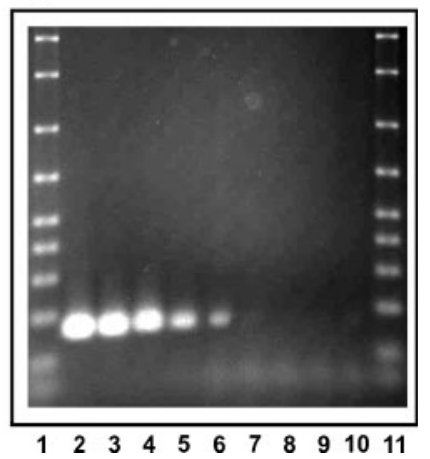

Fig. 1. Detection limits of the $r e c A$ gene-based MP-ST-PCR. Agarose gels of the partial recA PCR products amplified with $10^{6}, 10^{5}, 10^{4}, 10^{3}, 10^{2} 10,1$ and $0.1 \mathrm{fg}$ DNA (lanes 2-9, respectively) of O. anthropi LMG $3331^{\top}$ (a), O. intermedium LMG $3301^{\top}$ (b) and B. melitensis $16 \mathrm{M}^{\top}$ (c). Lane 10, no-template control; lanes 1 and 11, molecular mass standards. 
(a)

\begin{tabular}{|c|c|c|c|c|}
\hline & P... & Name & Calculate... & Cros... \\
\hline & 1 & I1 Placental fluid & & \\
\hline & 2 & 12a Placenta & $0.000 E+00$ & 30.13 \\
\hline & 3 & I 2b Placenta & & \\
\hline & 4 & I 3 Mother Lung & $<0.000 E+00$ & $>41.00$ \\
\hline- & 5 & 14 Mother Liver & & \\
\hline & 6 & 15 Mother Spleen & $0.000 E+00$ & 37.00 \\
\hline & 7 & 16 Mother Kidney & & \\
\hline & 8 & $17 \mathrm{M}$. Uterus Left Horn & $0.000 E+00$ & 28.94 \\
\hline- & 9 & 18 M. Uterus Right Horn & $0.000 E+00$ & 34.92 \\
\hline & 10 & I 9 Milk Right Udder & $0.000 E+00$ & 32.01 \\
\hline & 11 & I 10 Milk Left Udder & $0.000 E+00$ & 24.00 \\
\hline & 12 & I 11 Mother Urine & & \\
\hline$\longrightarrow$ & 13 & \| 1 Black Lamb Kidney & & \\
\hline & 14 & II 2 Black Lamb Liver & & \\
\hline & 15 & II 3 Black Lamb Lung & & \\
\hline & 16 & II 4 Black Lamb Spleen & & \\
\hline & 17 & II 5 Black Lamb Urine & $0.000 E+00$ & 38.98 \\
\hline & 18 & II 6 Black Lamb Stomach C & & \\
\hline & 19 & II 7 White Lamb Lung & & \\
\hline & 20 & II 8 White Lamb Liver & & \\
\hline & 21 & II 9 White Lamb Kidney & & \\
\hline & 22 & II 10 White Lamb Stomach & & \\
\hline & 23 & III 1 White Lamb EDTA & $0.000 E+00$ & 37.87 \\
\hline & 24 & III 2 Black Lamb EDTA & & \\
\hline 0 & 25 & III 3 Mother EDTA 5 days & & \\
\hline & 26 & III 4 Mother EDTA 7 days & & \\
\hline & 27 & III 5 White Lamb Serum & & \\
\hline 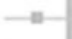 & 28 & III 6 Black Lamb Serum & & \\
\hline & 29 & III 7 Mother Serum 3 days & & \\
\hline & 30 & III 8 Mother Serum 5 days & & \\
\hline 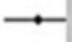 & 31 & III 9 Mother Serum 7 days & & \\
\hline & 32 & Non-template control & & \\
\hline
\end{tabular}

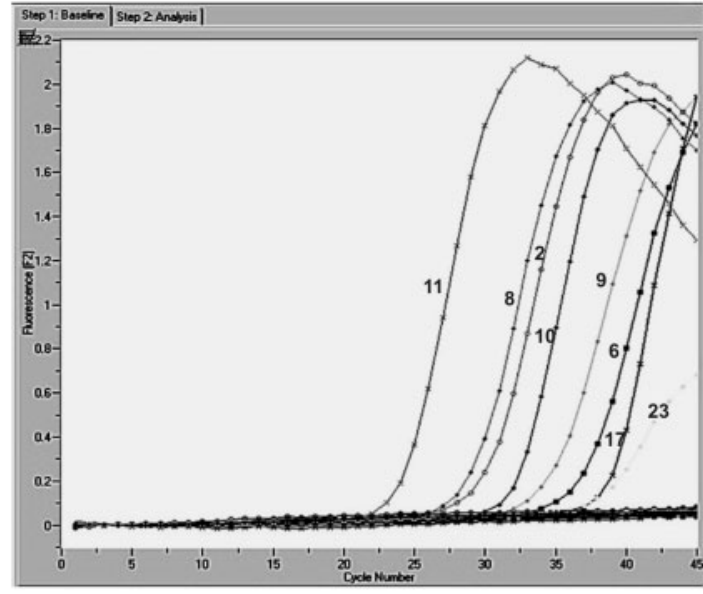

(b)

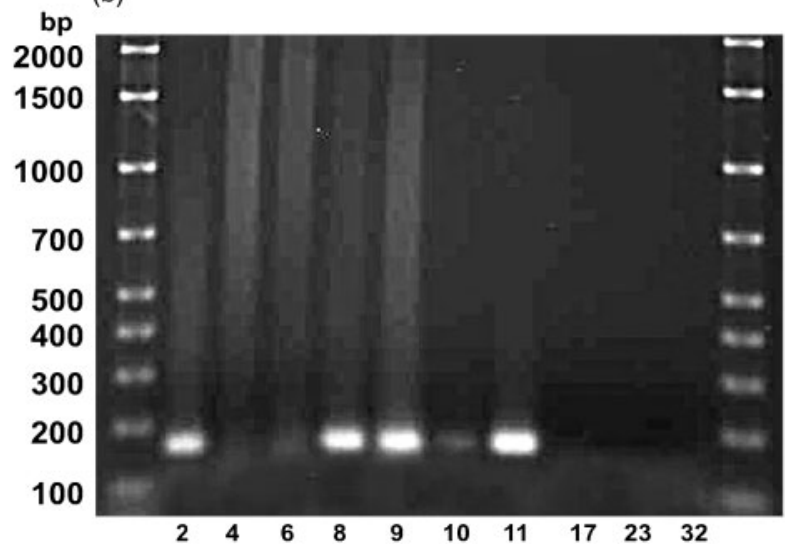

Fig. 2. Detection of Brucella DNA in clinical samples by real-time PCR (a) and the recA-based MP-ST-PCR (b). Clinical samples that were used are shown on the left in (a). The numbers of the samples that were positive in the real-time PCR are given on the corresponding amplification curves. Samples with a $C_{t}$ value of $<37$ were positive in both PCR assays.

Templates with a $C_{\mathrm{t}}$ value of $>37($ nos 4,17 and 23$)$ were negative. Thus, both PCR assays exhibited almost equal detection limits. Brucella DNA was also amplified from liver abscess material from a patient with culture-proven brucellosis (data not shown). The applicability of the assay for the detection of $O$. anthropi and O. intermedium in clinical specimens could not be investigated as no clinical material was available, but it can be assumed that no loss in analytical sensitivity would occur.

Our results demonstrate that the developed PCR assay allows accurate differentiation of $O$. anthropi, O. intermedium and Brucella spp. The developed assay is intended mainly for use with pure cultures where biochemical tests have given uninterpretable results. Although we demonstrated that the developed PCR can also be used for the specific and sensitive detection of Brucella DNA in different tissues, we recommend well-evaluated real-time PCRs for the detection of Brucella in clinical samples, as investigated by Al Dahouk et al. (2007).

\section{ACKNOWLEDGEMENTS}

We are grateful to C. Lodri, S. Schatz and I. Patzwald for excellent technical assistance.

\section{REFERENCES}

Al Dahouk, S., Tomaso, H., Noeckler, K. \& Neubauer, H. (2004). The detection of Brucella spp. using PCR-ELISA and real-time PCR assays. Clin Lab 50, 387-394.

Al Dahouk, S., Noeckler, K., Scholz, H. C., Pfeffer, M., Neubauer, H. \& Tomaso, H. (2007). Evaluation of genus-specific and speciesspecific real-time PCR assays for the identification of Brucella spp. Clin Chem Lab Med,

Alnor, D., Frimodt-Moller, N., Espersen, F. \& Frederiksen, W. (1994). Infections with the unusual human pathogens Agrobacterium species and Ochrobactrum anthropi. Clin Infect Dis 18, 914-920.

Apisarnthanarak, A., Kiratisin, P. \& Mundy, L. M. (2005). Evaluation of Ochrobactrum intermedium bacteremia in a patient with bladder cancer. Diagn Microbiol Infect Dis 53, 153-166. 
Baily, G. G., Krahn, J. B., Drasar, B. S. \& Stoker, N. G. (1992). Detection of Brucella melitensis and Brucella abortus by DNA amplification. J Trop Med Hyg 95, 271-275.

Elsaghir, A. A. \& James, E. A. (2003). Misidentification of Brucella melitensis as Ochrobactrum anthropi by API 20NE. J Med Microbiol 52, 441-442.

Garcia-Yoldi, D., Marin, C. M., de Miguel, M. J., Munoz, P. M., Vizmanos, J. L. \& Lopez-Goni, I. (2006). Multiplex PCR assay for the identification and differentiation of all Brucella species and the vaccine strains Brucella abortus S19 and RB51 and Brucella melitensis Rev1. Clin Chem 52, 779-781.

Hubalek, Z., Scholz, H. C., Sedlaceck, I., Melzer, F., Sanogo, Y. \& Nesvadbova, J. J. (2007). Brucellosis of the common vole (Microtus arvalis). Vector Borne Zoonotic Dis (in press).

Kämpfer, P., Citron, D. M., Goldstein, E. J. C. \& Scholz, H. C. (2007), Difficulty in the identification and differentiation of clinically relevant Ochrobactrum species. J Med Microbiol 56, 1571-1573.

Kettaneh, A., Weill, F. X., Poilane, I., Fain, O., Thomas, M., Herrmann, J. L. \& Hocqueloux, L. (2003). Septic shock caused by Ochrobactrum anthropi in an otherwise healthy host. J Clin Microbiol 41, 1339-1341.

Mahmood, M. S., Sarwari, A. R., Khan, M. A., Sophie, Z., Khan, E. \& Sami, S. (2000). Infective endocarditis and septic embolization with Ochrobactrum anthropi: case report and review of literature. J Infect 40, 287-290.

Möller, L. V. M., Arends, J. P., Hermsen, H. J. M., Talens, A., Terpstra, P. \& Slooff, M. J. H. (1999). Ochrobactrum intermedium infection after liver transplantation. J Clin Microbiol 37, 241-244.

Ozdemir, D., Soypacaci, Z., Sahin, I., Bicik, Z. \& Sencan, I. (2006). Ochrobactrum anthropi endocarditis and septic shock in a patient with no prosthetic valve or rheumatic heart disease: case report and review of the literature. Jpn J Infect Dis 59, 264-265.
Pappas, G., Panagopoulou, P., Christou, L. \& Akritidis, N. (2006). Brucella as a biological weapon. Cell Mol Life Sci 63, 2229-2236.

Perez-Blanco, V., Gacia-Caballero, J., Dominguez-Melcon, F. J. \& Gomez-Limon, I. M. (2005). Ochrobactrum anthropi infectious endocarditis in an immunocompetent patient. Enferm Infecc Microbiol Clin 23, 111-112 (in Spanish).

Romero Gomez, M. P., Peinado Esteban, A. M., Sobrino Daza, J. A., Saez Nieto, J. A., Alvarez, D. \& Pena Garcia, P. (2004). Prosthetic mitral valve endocarditis due to Ochrobactrum anthropi: case report. J Clin Microbiol 42, 3371-3373.

Scholz, H. C., Tomaso, H., Al Dahouk, S. A., Witte, A., Schloter, M. \& Kämpfer, P. (2006). Genotyping of Ochrobactrum anthropi by recAbased comparative sequence, PCR-RFLP, and 16S rRNA gene analysis. FEMS Microbiol Lett 257, 7-16.

Teyssier, C., Marchandin, H., Jean-Pierre, H., Diego, I., Darbas, H., Jeannot, J. L., Gouby, A. \& Jumas-Bilak, E. (2005). Molecular and phenotypic features for identification of the opportunistic pathogens Ochrobactrum spp. J Med Microbiol 54, 945-953.

Tomaso, H., Reisinger, E. C., Al Dahouk, S., Frangoulidis, D., Rakin, A., Landt, O. \& Neubauer, H. (2003). Rapid detection of Yersinia pestis with multiplex real-time PCR assays using fluorescent hybridisation probes. FEMS Immunol Med Microbiol 38, 117-126.

Vaidya, S. A., Citron, D. M., Fine, M. B., Murakami, G. \& Goldstein, E. J. C. (2006). Pelvic abscess due to Ochrobactrum intermedium [corrected] in an immunocompetent host: case report and review of the literature. J Clin Microbiol 44, 1184-1186.

Velasco, J., Romero, C., López-Goñi, I., Leiva, J., Diaz, R. \& Moriyón, I. (1998). Evaluation of the relatedness of Brucella spp. and Ochrobactrum anthropi and description of Ochrobactrum intermedium sp. nov., a new species with a closer relationship to Brucella spp. Int $J$ Syst Bacteriol 48, 759-768. 